\title{
Paget's disease of the bone (early diagnosis): How far is far away?
}

\author{
Assoc. Prof. Adina GHEMIGIAN ${ }^{1,2}$, MD, PhD, Assist. Prof. Mara CARSOTE ${ }^{1,2}$, MD, PhD, \\ Andra COCOLOS ${ }^{1,2}, \mathrm{MD}$, PhD student, Nicoleta DUMITRU ${ }^{1,2}, \mathrm{MD}, \mathrm{PhD}$ student, \\ Assist. Prof. Eugenia PETROVA ${ }^{1}, \mathrm{MD}, \mathrm{PhD}$, Lecturer Ana VALEA ${ }^{3,4}, \mathrm{MD}, \mathrm{PhD}$, Raluca MUNTEAN ${ }^{5}, \mathrm{MD}$, \\ Andrei GOLDSTEIN², MD, PhD student \\ 1"Carol Davila" University of Medicine and Pharmacy, Bucharest \\ 2"C.I. Parhon" National Institute of Endocrinology, Bucharest \\ 3"I. Hatieganu" University of Medicine and Pharmacy, Cluj-Napoca \\ ${ }^{4}$ Clinical County Hospital, Cluj-Napoca \\ "'Gral Medical", Bucharest
}

\begin{abstract}
Introduction. Paget's disease of the bone is a skeleton condition affecting bone remodelling of unknown cause. Bone formation and resorption, as parts of bone turnover which are normally coupled in healthy skeleton, in this condition are disconnected. We aim to introduce an adult male case with the condition which is also diagnosed with a multinodular goitre. This is a case report. This is a 60-year old male who is a former smoker and recently accused intermittent mild loss of hearing at left ear. Whole body bone scintigram $(20 \mathrm{mCi}, \mathrm{Tc} 99 \mathrm{~m})$ showed increased uptake of the radiotracer with high bone affinity at parietal and occipital parts of the skull. Accidental multinodular goitre is diagnosed with a large cystic macronodule. Fine needle aspiration showed BETHESDA 2 with modest risk of haemorrhage and indication of surgery. 6 months after a dose of $5 \mathrm{mg}$ zolendronic acid the bone markers were not increased and subsequent follow-up is necessary.

Conclusion. Early diagnosis of Paget's bone disease improves the potential risk of complications; however, distant potential complications need lifelong periodic check-up. The synchronous diagnosis of multinodular goitre with dominant cystic macronodule seems accidental in this male case.
\end{abstract}

Keywords: Paget's disease, bone, skull

\section{INTRODUCTION}

Paget's disease of the bone is a skeleton condition affecting bone remodelling of unknown cause $(1,2)$. Some viral infections are found in correlation with the disease while others observations are connected to a genetic susceptibility $(1,2)$. Other conditions have been linked to Paget's diseases as meningiomas, probably based on common genetic background but this aspect is less described up to this moment (3). Early stages involve the increased activity of osteoclasts causing bone resorption which represents a call for osteoblasts as further contributors to bone formation $(1,4)$. These two parts of bone turnover which are normally coupled in healthy skeleton, in this condition are disconnected $(4,5)$. Early clinical and paraclinical diagnosis may include only an abnormal rise of alkaline phosphatase, incidental abnormal bone features as those described at plane X-Rays (1-5). Many incidental anomalies are part o daily en- 
docrine practice including tumours displayed as incidentalomas, they are actually accidentally registered by endocrinologists or radiologists etc. (6). A part from osteoporosis in men and peak bone mass associated anomalies, skeleton is also affected in males with Paget's disease like bone pain, enlarged skull and secondary hearing damage or enlarged long bones $(1,7,8)$. We aim to introduce an adult male case with the mentioned bone condition who is also diagnosed with a multinodular goitre by the same time. This is a case report. The patient agreed for anonymously use of his medical data. He was followed in different medical centres from Romania.

\section{CASE REPORT}

\section{Paget's bone disease: First step of diagnosis}

This is a 60-year old male (coming from non-endemic area) who is a former smoker and recently accused intermittent mild loss of hearing at left ear, as well as chronic asthenia. His medical background includes chronic rhinitis. His family history is unrevealing. After a clinical examination as an outpatient he was referred for a cranial computed tomography and Paget's bone disease was suspected. He was further admitted for an endocrine check-up. Clinical exam is normal, except for enlarged multinodular goitre.

TABLE 1. Bone metabolism on a 60-year old male confirmed with Paget's bone disease

\begin{tabular}{|c|c|c|c|}
\hline Parameter & Value & Normal ranges & Units \\
\hline \multirow{2}{*}{$\begin{array}{l}\text { Total serum } \\
\text { calcium }\end{array}$} & 9.4 & $8.4-10.2$ & \multirow[t]{2}{*}{$\mathrm{mg} / \mathrm{dl}$} \\
\hline & $9.5^{*}$ & & \\
\hline \multirow{2}{*}{$\begin{array}{l}\text { lonic serum } \\
\text { calcium }\end{array}$} & 4.12 & $3.9-4.9$ & \multirow[t]{2}{*}{$\mathrm{mg} / \mathrm{dl}$} \\
\hline & $4.18^{*}$ & & \\
\hline \multirow{2}{*}{$\begin{array}{l}\text { Alkaline } \\
\text { phosphatase }\end{array}$} & 54 & $40-150$ & \multirow[t]{2}{*}{$\mathrm{U} / \mathrm{I}$} \\
\hline & $38^{*}$ & & \\
\hline \multirow[t]{2}{*}{ osteocalcin } & 21.12 & $14-46$ & \multirow[t]{2}{*}{$\mathrm{ng} / \mathrm{ml}$} \\
\hline & $12^{*}$ & & \\
\hline \multirow[t]{2}{*}{ CrossLaps } & 0.75 & $0.104-0.504$ & \multirow[t]{2}{*}{$\mathrm{ng} / \mathrm{ml}$} \\
\hline & $0.33^{*}$ & & \\
\hline \multirow[t]{2}{*}{ P1NP } & 77.33 & $15-74$ & \multirow[t]{2}{*}{$\mathrm{ng} / \mathrm{ml}$} \\
\hline & $33^{*}$ & & \\
\hline \multirow{2}{*}{$\begin{array}{l}\text { 25-hydroxyvitamin } \\
\text { D }\end{array}$} & 18.2 & $30-100$ & \multirow[t]{2}{*}{$\mathrm{ng} / \mathrm{ml}$} \\
\hline & $33 *$ & & \\
\hline \multirow[t]{2}{*}{ Parathormone } & 36.81 & $15-65$ & \multirow[t]{2}{*}{$\mathrm{pg} / \mathrm{mlL}$} \\
\hline & $44 *$ & & \\
\hline
\end{tabular}

Blood assay of mineral metabolism revealed a mild increase of bone formation marker P1NP and bone resorption marker CrossLaps, as introduced in Table 1. He also associated vitamin D deficiency (Table 1). Central DXA (Dual-Energy $\mathrm{X}$-Ray Absorptiometry) is normal (Fig. 1). Whole body bone scintigram $(20 \mathrm{mCi}, \mathrm{Tc} 99 \mathrm{~m})$ showed increased uptake of the radiotracer with high bone affinity at parietal and occipital parts of the skull, and some irrelevant chronic degenerative aspects in others body parts (Fig. 2). The patient was offered zolendronic acid (through intravenous route, $5 \mathrm{mg}$ ) in association with high doses of cholecalciferol (4,000 Units per day for 2 months followed by a maintenance dose of daily 2,000 UI in association with daily $800 \mathrm{mg}$ calcium).

\section{Accidental detection of multinodular goitre}

By the same time, thyroid panel of investigations revealed normal function, and calcitonin with negative specific antibodies against thyroid. Thyroid ultrasound confirmed a right lobe of 1.9 by 2.4 by $4.3 \mathrm{~cm}$ (centimetre) with hypoechoic, inhomogeneous pattern associating a small nodule of $0.37 \mathrm{~cm}$, and another of oval, well defined shape (of 1.5 by 1.2 by $1.3 \mathrm{~cm}$ ), and another of $1.24 \mathrm{~cm}$ maximum diameter (Fig. 3). Left thyroid lobe has 4.2 by 5.4 by $6.8 \mathrm{~cm}$ being in majority displayed by a large macronodule with majority cystic component, of 4.1 by 4 by $4.5 \mathrm{~cm}$, with a mild peripheral vascularisation, and another nodule on the isthmus of 1.3 by 0.6 $\mathrm{cm}$ (Fig. 3). No suspected lymph node enlargement is detected at cervical ecographic examination. Fine needle aspiration showed BETHESDA 2 risk of malignancy, with rapid refill of the cystic area after complete evacuation, associating a modest risk of intra-nodular haemorrhage which indicates total thyroidectomy.

\section{Follow-up}

6 months later, the patient was re-admitted for follow-up. Clinical exam was normal. DXA showed no bone loss. Bone turnover markers indicated a small reduction of alkaline phosphatase and osteocalcin (Table 1). Current doses of vitamin D and calcium supplements was further recommended, and a second evaluation is scheduled which another 6 months.

\section{DISCUSSION}

This is an adult case diagnosed by the age of 60 with Paget's disease of monoostotic type. The condition is early diagnosed based on mild 
Practica Medicală - Vol. 13, Nr. 2(57), An 2018
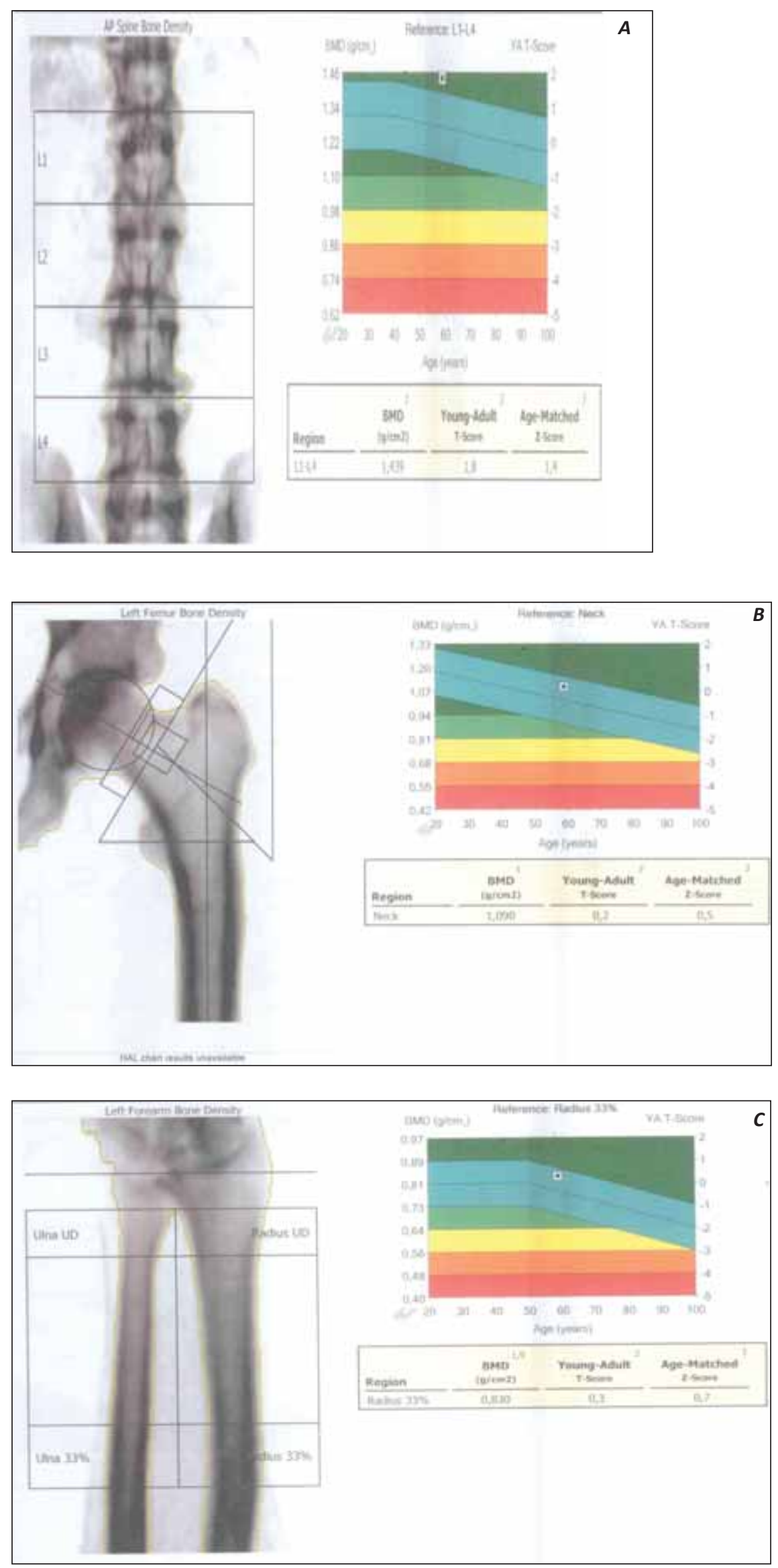

FIGURE 1. Central DXA on a 60-year old male newly diagnosed with Paget's bone disease (normal results). A. lumbar spine; B. femoral neck; C. third distal forearm 


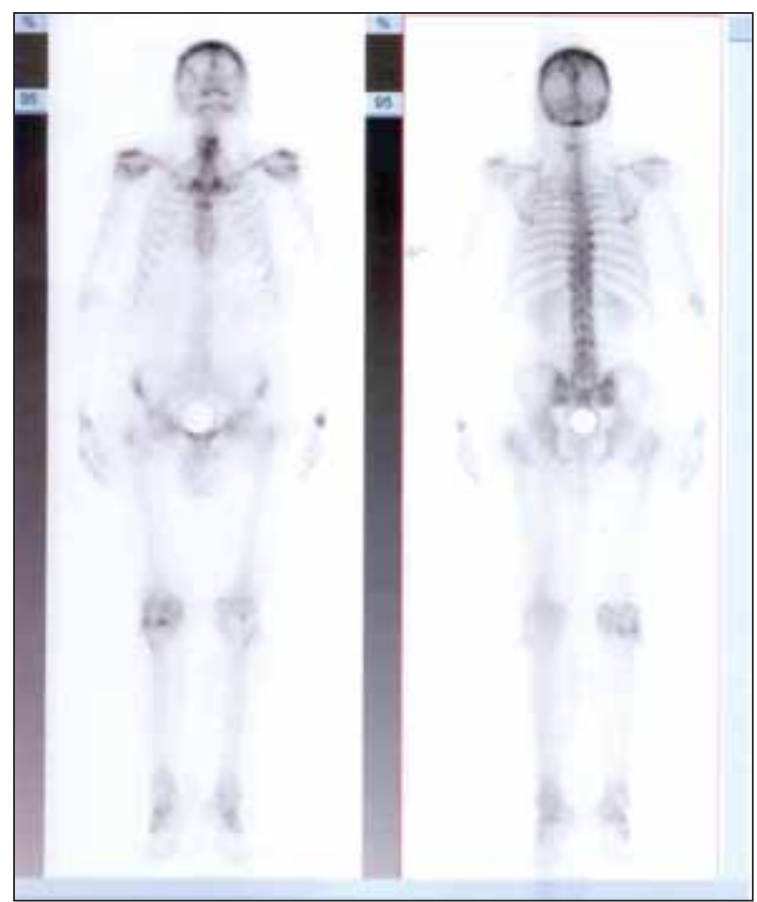

FIGURE 2. Whole body bone scintigram (20mCi, Tc99m) showed increased uptake of the radiotracer with high bone affinity at parietal and occipital parts of the skull, and some irrelevant chronic degenerative aspects in others body parts.

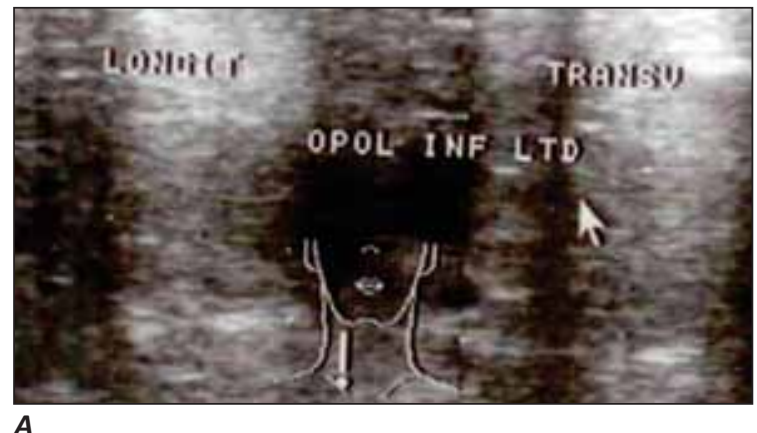

A

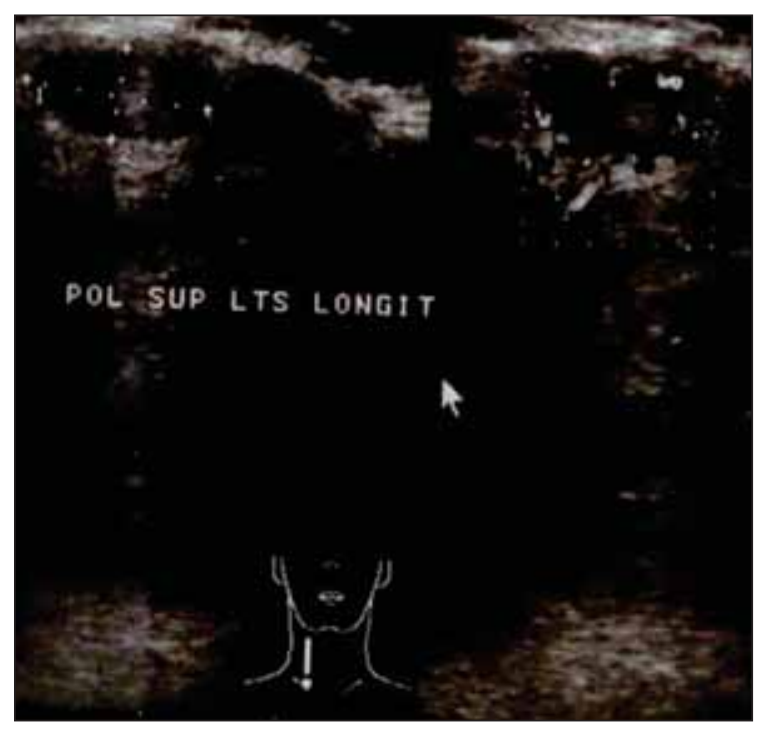

$B$

FIGURE 3. Thyroid ultrasound confirmed a right lobe of 1.9 by 2.4 by $4.3 \mathrm{~cm}$ (centimetre) with hypoechoic, inhomogeneous pattern associating a small nodule of $0.37 \mathrm{~cm}$, and another of oval, well defined shape (of 1.5 by 1.2 by $1.3 \mathrm{~cm}$ ), and another of $1.24 \mathrm{~cm}$ maximum diameter (A) Left thyroid lobe has 4.2 by 5.4 by $6.8 \mathrm{~cm}$ being in majority displayed by a large macronodule with majority cystic component, of 4.1 by 4 by $4.5 \mathrm{~cm}$, with a mild peripheral vascularisation $(B, C)$ clinical anomalies and mostly based on bone whole body scintigraphy which is considered the most sensitive test $(1,9)$. Typically, the disease is rarely diagnosed before the age of 40 ; it has an age-dependent pattern; some data suggests a 2-3\% prevalence in people older than 55 years (as seen in our case) (9). Therapy of choice includes intravenous bisphosphonates as zolendronic acid, pamidronate or oral drugs as alendronate, risendronate, as well as calcitonin as a second-line option (9). In this case, we used zolendronic acid with a very good clinical response, also registering an adequate bone turnover profile. No second dose is necessary up to this moment. Serial bone scans are necessary as well as plane $\mathrm{X}$-ray based on bone pain, alkaline phosphatase pattern (9). In this particular situation, local complications are hear loss and general risk of osteosarcoma which is higher than in general population need careful periodic checkup (9). Even bone, both normal and pathological, is tidily related to multiple other bio-neuro-endocrine molecules as 5-hydroxytriptamine or lipid profile, the discovery of multinodule goitre seems incidental here $(10,11)$.

\section{CONCLUSION}

Early diagnosis of Paget's bone disease improves the potential risk of complications; how-

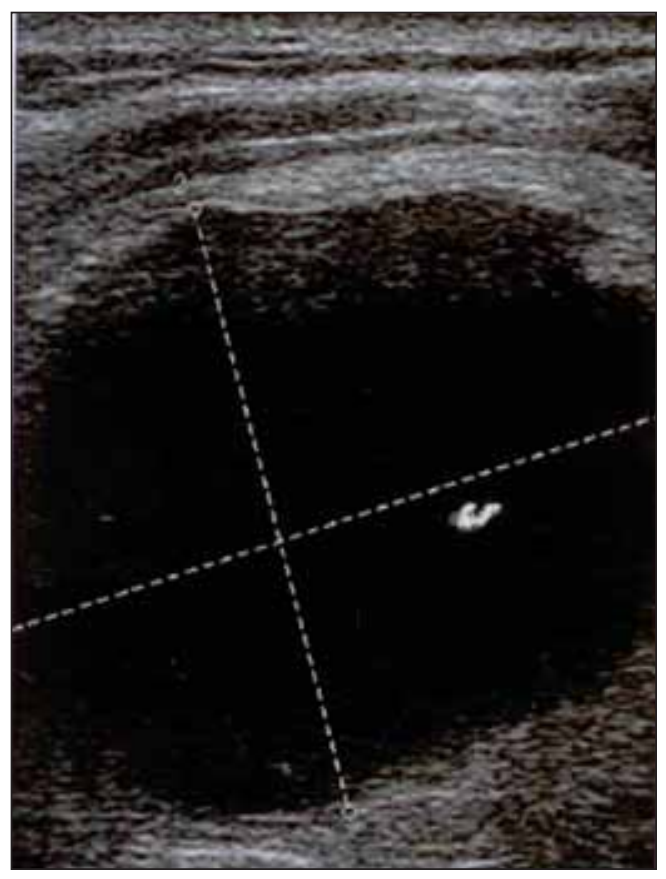

c 
ever, distant potential complications need lifelong periodic check-up. The synchronous diagnosis of multinodular goitre with dominant cystic macronodule seems accidental in this male case.

\section{REFERNCES}

1. Glendenning P., Chubb S.A.P., Vasikaran S. Clinical utility of bone turnover markers in the management of common metabolic bonediseases in adults. Clin Chim Acta. 2018 Jun;481:161-170.

2. Kravets I. Paget's disease of bone: Diagnosis and treatment. Am J Med. 2018 May 9. pii: S0002-9343(18)30405-4. doi: 10.1016/j.amjmed.2018.04.028. [Epub ahead of print]

3. Poiana C., Carsote M., Hortopan D., Coculescu M. Skull monoostotic Paget's disease of the bone. Case report and review of the literature, Acta Endocrinologica, 2007; III(3):333-344.

4. Rolvien T., Butscheidt S., Zustin J., Amling M. Skeletal dissemination in
Paget's disease of the spine. Eur Spine J. 2018 Jan 17. doi: 10.1007/s00586-0185477-4. [Epub ahead of print]

5. Cundy T. Paget's disease of bone. Metabolism. 2018 Mar; 80:5-14. doi: 10.1016/j.metabol.2017.06.010.

6. Gheorghisan-Galateanu A.A., Carsote M., Valea A. Incidentaloma: From general practice to specific endocrine frame. J Pak Med Assoc. 2017.67(6):917-922.

7. Carsote M., Valea A. Insights of peak bone mass. Acta Medica Transilvanica. 2016; 21(2):82-85. ISSN 2285-7079, ISSN-L 1453-1968.

8. Carsote M., Valea A., Ghemigian A., Dumitrache $\mathbf{C}$. Osteoporosis in men: therapy options based on etiological diagnosis. Current Health Sciences Journal. 2016; 42(S5):46-48

9. Singer F.R., Bone H.G. 3rd, Hosking D.J., Lyles K.W., Murad M.H., Reid I.R., Siris E.S.; Endocrine Society. Paget's disease of bone: An endocrine society clinical practice guideline. J Clin Endocrinol Metab. 2014 Dec; 99(12):4408-22.

10. Carsote M., Paduraru D.N., Nica A.E., Valea A., Ghemigian A.

5-Hydroxytryptamine and skeleton status. Romanian Medical Journal (Revista Medicala Romana). 2016; LXIII(4):293-296

11. Poiana C., Radoi V., Carsote M., Bilezekian J. New Clues that May Link Osteoporosis to the Circulating Lipid Profile. Bone Research 2013; 1(3):260-266. 